\title{
Transport of ions at the mineral fluid interface: insights from the copper sulfide system
}

\author{
AloK ChaUdhari*1 ${ }^{*}$, ANDREW Frierdich ${ }^{1}$, Helen E. \\ A. BRAND ${ }^{2}$, DAVID PATERSON ${ }^{2}$, RAHUL RAM ${ }^{1}$, \\ BARBARA ETSCHMANN $^{1}$, JOËL BRUGGER ${ }^{1}$ \\ ${ }^{1}$ School of Earth Atmosphere and Environment Sciences, \\ Monash University, Melbourne, Australia, 3800 \\ ${ }^{2}$ Australian Synchrotron, ANSTO, Blackburn Road, Clayton, \\ VIC 3168, Australia
}

(*correspondence: alok.chaudhari@monash.edu)

The mineral-fluid interface plays an important role in facilitating the exchange of ions (cations and anions) in geological system. We have undertaken a combined in-situ and ex-situ experimental study into the nature of ion transport during the mineral replacement reaction of chalcopyrite $\left(\mathrm{CuFeS}_{2}\right)$ by covellite $(\mathrm{CuS})$ and/or digenite $\left(\mathrm{Cu}_{1.8} \mathrm{~S}\right)$ in copper-rich aqueous solution and at mild hydrothermal conditions $\left(180-300{ }^{\circ} \mathrm{C}\right)$. The mineral replacement of chalcopyrite by covellite and digenite is a model for complex, redox-active geochemical reactions; a common reaction in ore deposits; and an emerging method in hydrometallurgy to upgrade low grade copper minerals. The replacement of chalcopyrite by covellite and digenite proceeds via the removal of $\mathrm{Fe}^{2+}$ ions from chalcopyrite leading to the formation of covellite, and the uptake of $\mathrm{Cu}(\mathrm{aq})$ ions to form digenite. In-situ synchrotron-based powder diffraction experiments revealed the complex nature of reaction kinetics during chalcopyrite replacement. Modelling of reaction kinetics based on the Avrami model suggests a two-stage mechanism; covellite forms initially via a 3-dimensional growth mechanism, followed by diffusion-controlled growth of covellite and/or digenite. The formation of a three dimensional layer of covellite acts as an important mineralfluid interface controlling the formation of digenite during the replacement reaction by controlling the $\mathrm{Cu}, \mathrm{Fe}$, and redox conditions at the reaction interface. To investigate the mobility of anions during the mineral replacement reaction, series experiments were conducted with added CuSe. Dissolution of CuSe into selenium ions at high temperatures was observed, further in-situ synchrotron based X-ray fluorescence mapping of the replacement products revealed the enrichment of selenium only in the covellite layer, suggesting the limited diffusion of anions across the mineralfluid boundary during the mineral replacement reaction. 